\title{
Is Cost of Locomotion the Reason for Prolonged Nesting Forays of Snapping Turtles, Chelydra serpentina?
}

\author{
Shane R. DE Solla and Kim J. FERnie \\ Canadian Wildlife Service, Environment Canada, Canada Centre for Inland Waters, 867 Lakeshore Road, P.O. Box 5050, \\ Burlington, Ontario L7R 4A6 Canada
}

de Solla, Shane R., and Kim J. Fernie. 2004. Is cost of locomotion the reason for prolonged nesting forays of Snapping Turtles, Chelydra serpentina? Canadian Field-Naturalist. 118(4): 610-612.

Prolonged nesting forays were observed in five gravid Snapping Turtles (Chelydra serpentina), in 1999 and 2001 . For all observations, the females began exploratory nest excavations but failed to oviposit. Subsequently, all five females sought refuge either by burying themselves in substrate, or by seeking shade under vegetation, presumably to wait until the following day to resume nesting activities. By contrast, most observations of failed nesting resulted in the females abandoning the nesting site and returning immediately to water. Although prolonged nesting attempts in other turtle species (i.e. kinosternids) likely are associated with rainfall or predation risk, we speculate that these prolonged nesting attempts in Snapping Turtles reduced the cost of terrestrial travel.

Key Words: Snapping Turtles, Chelydra serpentina, oviposition, nesting behaviour, cost of locomotion, Ontario

Nesting behaviour of Snapping Turtles (Chelydra serpentina) has been described in detail elsewhere (see Ernst et al. 1994), and is generally characterized by behaviour that minimizes exposure on terrestrial habitats. Briefly, nesting behaviour starts with emergence from water, followed by nest site selection. Females typically dig with their front limbs, and often poke their noses into the substrate, presumably to determine if the soil type and/or hydration are adequate. Subsequently, the rear limbs are used first to excavate the nest cavity, then position the eggs during oviposition, and finally to bury the eggs. Subsequently, the female leaves the nesting area, and returns to the water. Although Snapping Turtles have been known to travel more than $0.5 \mathrm{~km}$ overland to nesting sites (Obbard and Brooks 1980), normally they nest at a site much closer to the water. Regardless if the female was successful in nesting or not, generally she returns to water immediately afterwards. Nesting normally occurs in the early morning or late evening, although females may nest in the afternoon following rain. By minimizing the distance or time traveled on land, female Snapping Turtles may avoid energetic costs, or the risks of dehydration or predation. Baudinette et al. (2000) found that terrestrial locomotion was 2.6 times more energetically costly than aquatic locomotion for the Murray Short-necked Turtle (Emydura macquarii). Snapping Turtles are particularly vulnerable to water loss compared to other turtles (Ernst 1968) due to their exposed skin. Although depredation of adults is rare, adult females are occasionally taken by large predators, such as bears or coyotes (Ernst et al. 1994). Here we document five instances of prolonged nesting forays in Snapping Turtles, which have not previously been documented, and discuss possible reasons for this behaviour.

\section{Study Site}

Observations were made from two locations in Ontario, both known for many years to be nesting sites for Snapping Turtles. The first nesting site, the northwestern shoreline of Coote's Paradise, Hamilton $\left(43^{\circ} 16^{\prime} \mathrm{N}, 79^{\circ} 56^{\prime} \mathrm{W}\right)$, consists primarily of a community vegetable garden and a wood chip pile on Ontario Power Generation property. The nesting site is separated from the open water by approximately $150 \mathrm{~m}$, first by a steep hill with thick shrub cover, and secondly by dense cattails. The second nesting site, at Wheatley Provincial Park $\left(42^{\circ} 5^{\prime} \mathrm{N}, 82^{\circ} 26^{\prime} \mathrm{W}\right)$, consists of a series of sand, dirt, and wood chip piles in a maintenance area. Although normally open water is relatively close to the nesting site $(\sim 50 \mathrm{~m})$, in 2001 when the observations were made, water levels were extremely low, and most water in the park had drained into Lake Erie, leaving bare mudflats. We observed many turtle tracks in the exposed mud leaving the park into Lake Erie (de Solla, personal observation). Thus, at both sites, the nesting females did not have nearby access to water.

\section{Nesting Observations}

De Solla et al. (2001) reported the deaths of two gravid Snapping Turtles that buried themselves in a composting wood chip pile at Cootes Paradise, Hamilton, on 7 and 9 June 1999. Both gravid turtles remained in the wood chip pile until their deaths. Results of postmortem examinations were consistent with death due to hyperthermia (de Solla et al. 2001); however, no reasons for their behaviour were suggested. The behaviour of both females was consistent for females searching for suitable nesting sites, except after failing to successfully nest, both buried themselves in the wood chip pile. A third female Snapping Turtle was also observed 8 June 1999 on the wood chip pile. Follow- 
ing apparently unsuccessful attempts to nest, the female was observed to be motionless for a few hours under the shade of burdock (Arctium spp.) and other vegetation, which provided the only shade in the area. De Solla did not touch her until later in the morning, but the turtle was found to be gravid. She remained in the shade after being disturbed.

On 9 June 2001 at 1045, a female turtle was found on a storage area for sand, dirt, and wood chips at Wheatley Provincial Park. There were numerous tracks on both the wood chips and dirt piles, possibly by more than one female. There was abundant shade at this site. She was sitting in shade under vegetation on a small dirt pile, with no apparent movement, and no evidence of nesting. She was left alone until 1200, at which time the female was about $2 \mathrm{~m}$ from her previous location, further in shade under vegetation. She did not move by 1300 . At this time she was palpated, found to be still gravid, and a blood sample was taken. She was released at the same spot she was found, where she remained for at least one hour, but she was not subsequently observed. No temperature readings were taken; however, the weather was sunny and hot.

On 12 June 2002, a female was seen in the vegetable garden at Coote's Paradise at approximately 2130 . Nearby were at least 10 digging attempts in freshly cultivated soil, and she was observed digging with her front limbs and poking her head into the soil. She was observed for approximately an hour, but did not show any signs of nesting. At approximately 2230 , she was observed to have buried herself, with only the top of her carapace showing. There was relatively little shade by vegetation available. At approximately 0745 hrs, 13 June 2002, a female was seen walking very near where the female from the previous night was observed. This female was heavily covered with dirt, suggesting that she was the same female that had buried herself. No nesting attempts were made by $1000 \mathrm{hrs;}$ subsequently we left and she was not observed again.

\section{Discussion}

The five observations of nesting attempts by Snapping Turtles had two common features; the delay was prior to oviposition, and the turtles sought terrestrial refuge by burying themselves in soil or wood chips, or by staying in shade. We have no observations of females remaining at the nesting ground after successful oviposition. We are unaware of any published reports of such behaviour in Snapping Turtles.

Various kinosternid species prolong their nesting forays, typically by burying themselves before and/or after oviposition (Iverson 1990; Burke et al. 1994; Wilson et al. 1999) adjacent to the nest. The duration of nest attendance in species other than Chelydra appears to be linked to the timing or duration of rainfall (Burke et al. 1994; Ernst et al. 1994). Intensive disturbance may also delay successful oviposition, and competitive nesting by Green Turtles (Chelonia mydas) at high densities may delay oviposition by a few days (Jessop et al. 1999). Typically, after a failed nesting attempt Snapping Turtles return to the wetland immediately following cessation of nesting behaviour (de Solla, persional observation).

We speculate that the prolonged nesting attempts we observed in Snapping Turtles was to avoid the cost of making a second trip between the water and nesting site. All instances of prolonged nesting attempts that we observed occurred a considerable distance from water. Abandoning a nesting attempt would therefore result in a relatively long journey to the water, and back again to the nest site for a second oviposition attempt. To avoid this cost, once a female aborts a nesting attempt, she may burrow under substrate or hide under vegetation until the following day. Females nesting closer to wetlands are more likely to leave the nest site and come back at a later time. At the Wildlife Research Station (Algonquin Park), Snapping Turtle nesting has been monitored on a dam at the southern end of Lake Sasajewun for $>25$ years, and all observed nesting attempts that failed were followed by the immediate withdrawal to the water $(\sim 5 \mathrm{~m})$ by the female (R. J. Brooks, University of Guelph, personal communication). Similarly, at eight other nesting sites in Ontario that the authors visited, all of which were close to wetland habitat, females withdrew to water following a failed nesting attempt. We did not count the number of these observations, but de Solla has frequently observed this behaviour.

In two of the five observations of prolonged nesting attempts, the turtles died of hyperthermia after burying themselves in composting wood chips (de Solla et al. (2001). We speculate that in most cases where females bury themselves, they use non-composting material, and thus are not at risk of hyperthermia.

\section{Acknowledgments}

We thank Wheatley and Algonquin Provincial Parks, and Ontario Power Generation for permission to enter their properties to look for turtle nests. Ron Brooks and anonymous reviewers gave valuable comments on earlier drafts.

\section{Literature Cited}

Baudinette R. V., A. M. Miller, and M. P. Sarre. 2000. Aquatic and terrestrial locomotory energetics in a toad and a turtle: a search for generalisations among ectotherms. Physiological and Biochemical Zoology 73: 672-682.

Burke V. J., J. W. Gibbons, and J. L. Greene. 1994. Prolonged nesting forays by common mud turtles (Kinosternon subrubrum). American Midland Naturalist 131: 190-195

de Solla S. R., D. Campbell, and C. A. Bishop. 2001. Hyperthermia induced mortality of gravid snapping turtles, Chelydra serpentina, and eggs in a wood chip pile. Canadian Field-Naturalist 115: 510-512.

Ernst, C. H. 1968. Evaporative water-loss relationships of turtles. Journal of Herpetology. 2: 159-161.

Ernst, C. H., J. E. Lovich, and R. W. Barbour. 1994. Turtles of the United States and Canada. Smithsonian Institution 
Press. Washington.

Iverson, J. B. 1990. Nesting and parental care in the mud turtle, Kinosternon flavescens. Canadian Journal of Zoology 68: 230-233.

Jessop, T. S., C. J. Limpus, and J. M. Whittier. 1999. Plasma steroid interactions during high-density green turtle nesting and associated disturbance. General and Comparative Endocrinology 115: 90-100.
Obbard M. E., and R. J. Brooks. 1980. Nesting migrations of the snapping turtle (Chelydra serpentina). Herpetologica 36: 158-162.

Wilson D. S., H. R. Mushinsky, and E. D. McCoy. 1999. Nesting behavior of the striped mud turtle, Kinosternon baurii (Testudines: Kinosternidae). Copeia. 1999: 958-968.

Received 11 October 2003

Accepted 23 November 2004 